\title{
Críticos del High-Tech, de Nadín Ospina
}

\author{
Critics of High-Tech, \\ Nadin Ospina
}

\author{
Diego Carrizosa Posada (Colombia) \\ Institución Universitaria Politécnico Grancolombiano \\ diegocarrizosa@gmail.com
}

\section{Resumen}

En este artículo el lector encontrará conceptos sobre el eurocentrismo, mediante los cuales se construirá una fundamentación teórica sobre las diferencias de superioridad e inferioridad entre culturas durante la etapa colonial y poscolonial en los países conquistados. Se hablará sobre las influencias recibidas del arte africano por parte de los artistas europeos pertenecientes a las primeras vanguardias, así como sobre los resultados que se obtienen en la forma de nuevos movimientos artísticos. Se reflexionará sobre el neologismo de lo glocal, de Robertson, que tiene

\begin{abstract}
In this article the reader will find concepts about Eurocentrism, through which a theoretical construction about the differences of superiority and inferiority between cultures during the colony and postcolony periods in the conquered countries will be elaborated. The article talks about the influences of African art by European artists belonging to the early avant-garde, as well as the results obtained in the form of new artistic movements. It will reflect on Robertson's neologism of the local, which has to do with mutual cooperation in the search for an equilibrium level between "the location of the global and
\end{abstract}

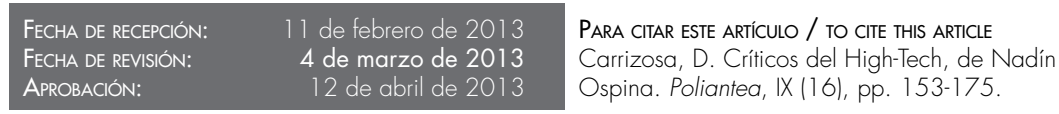


que ver con la mutua colaboración en la búsqueda de un nivel de equilibrio entre "la localización de lo global y globalización de lo local", con el fin de interpretar el concepto de la colaboración mutua entre las relaciones de poder, buscando deconstruir el concepto de dominio que se presenta entre el mundo desarrollado y el tercer y cuarto mundo dentro de la órbita artística. Es, entonces, como la obra conceptual del artista colombiano desempeña un papel fundamental en cuanto a los postulados explicados en este artículo, puesto que se basa en una iconografía de la cultura mediática del Primer Mundo, como es el caso del dibujo animado que representa a Bart Simpson.

Palabras clave: Nadín Ospina, Críticos del High Tech, eurocentrismo, localismo global, autoría, intervención y apropiacionismo. globalization of the local", to interpret the concept of the mutual cooperation between power relations, seeking to deconstruct the concept of dominance that occurs between the developed world and the third and fourth world within the artistic orbit. It is, then, how the conceptual work by the Colombian artist plays a critical role in terms of the principles discussed in this article, since it is based on a media culture iconography of the First World, such as the cartoon depicting Bart Simpson.

Keywords: Nadin Ospina, Critics of High Tech, eurocentrism, global localism, authorship, intervention and appropriation. 


\title{
Críticos del High-Tech, de Nadín Ospina
}

\begin{abstract}
Diego Carrizosa Posada (Colombia)
Bachiller en Artes, Profesional en Producción y Dirección de Cine y Televisión por el Columbia College de Los Ángeles, Estados Unidos. Cursó estudios en Crítica de Arte en la Universidad del Rosario en 1989. Fue galardonado con el Premio Nacional de Periodismo Simón Bolívar, otorgado a la serie Un día en la vida de... como el mejor programa cultural, en 1987. Actualmente, es profesor de tiempo

completo en el Departamento de Medios Audiovisuales del Politécnico Grancolombiano y adelanta estudios de Maestría en Estética e Historia del Arte en la Universidad Jorge Tadeo Lozano.
\end{abstract}

\section{Introducción}

La razón por la cual se ha planteado el tema de este artículo consiste en conocer las razones conceptuales y teóricas por las que el artista colombiano Nadín Ospina ha pensado y realizado la serie de múltiples titulada Críticos del High Tech, la cual fue expuesta en la Galería Arte 19 de Bogotá en 1993 (ver figuras 1, 2, 3 y 4). Se trata que el espectador que visita sus exposiciones, así como el lector de este texto, comprenda los eventos históricos, así como los postulados teóricos que se encuentran detrás de la fundamentación conceptual de una obra de arte, y de qué manera estas nociones se relacionan con la obra de Ospina. Para este efecto, contextualizaré de manera sucinta algunos hechos de la historia que tienen que ver con la evoloción de las artes plásticas en el mundo, que considero han ayudado construir el modo de pensar de nuestra sociedad y a fundamentar las teorías que han hecho que la visión del artista en el mundo de hoy tenga connotaciones "glocales".

Durante el desarrollo de este texto, hablaré acerca de la situación que se dio a comienzos del siglo XV durante la conquista en América, en lo que tiene que ver con juicios de superioridad e inferioridad entre las culturas, con las situaciones de progreso y atraso, con lo primitivo en contra de lo civilizado, nociones que habrían de tutelar los criterios estéticos que se pondrán en circulación, de acuerdo con el pensamiento eurocéntrico. 
Más adelante me referiré a las diferencias conceptuales que se dan dentro del marco de pensamiento que atañe a la modernidad, y que se presentan entre las realizaciones de arte étnico y de las artesanías, cuyo valor se entiende como de uso, y las obras de arte que provocan goce estético. A partir de allí, hablaré sobre las teorías de globalidad del sociólogo estadounidense Roland Robertson (1998), quien habla de la "glocalización", término que en sus palabras significa simultaneidad, copresencia de tendencias universales, al mismo tiempo que particulares, neologismo que rompe con los parámetros del pensamiento eurocéntrico. Posteriormente, relaciono las teorías del estadounidense con la exploración realizada por parte de importantes artistas europeos de las vanguardias, quienes, buscando romper con la academia tradicional, indagan sobre nuevas fuentes de inspiración y se remontan al arte étnico africano, como es el caso de Picasso, Vlaminck, Matisse y Giacometti; para este efecto, me baso en el referente que comprende algunas de las obras exhibidas en la exposición del MoMa de 1984, titulada Primitivism in 20th Century Art: Affinity of the Tribal and the Modern.
Una vez expuesta esta breve conceptualización sobre la historia y su relación con las artes, procedo, entonces, a explicar los postulados teórico-artísticos que han construido el camino para que Ospina pueda conceptualizar su obra Críticos del High-Tech. Como es el caso de las nociones del remake, de apropiación de una obra de arte para modificar sus tipologías y su autoría, así como las teorías que versan sobre los procesos de intervención y deconstrucción de una obra de arte.

Posteriormente, investigo qué tipo de postulados artísticos se pueden ver reflejados en Críticos del High-Tech, y encuentro que Nicolas Bourriaud, en Estética relacional, habla de las nociones sobre el papel del artista solitario en su búsqueda del gran concepto sobresaliente en el arte, que se refiere a la de la autoría de la obra, del apropiacionismo, así como del sentido del lugar de exhibición de esta, conceptos que emergen en el trabajo del colombiano. Otro autor, cuyos conceptos se encuentran en la obra de Ospina, es Jean Baudrillard, quien escribe en $E l$ gestual y la firma: semiurgia del arte contemporáneo, que el objeto se convierte en obra por medio de la firma, que es el signo que preserva la 
autenticidad de la obra. Se finaliza el artículo con el concepto de una coyuntura que instala la modernidad en la que los creadores del Tercer Mundo utilizan códigos visuales y formales para obtener una estrategia de movimiento en el que se homologan las diferentes expresiones artísticas del mundo, y que el concepto de Robertson (1998) de "la localización de lo global y globalización de lo local", convierte al artista Nadín Ospina, según palabras de Bourriaud, en un "semionauta, un artista que inventa trayectorias entre signos, navega entre signos" (2006, p. 142), y en mis palabras, que navega sin tener fronteras que limiten su poder.

\section{Postulados sobre eurocentrismo, fundamentaciones artísticas de las primeras vanguardias y teorías de localismo global}

En El arte latinoamericano en la encrucijada decolonial, el cual es publicado en 2009, la autora Zulma Palermo', escribe que si se piensa sobre la producción local, así su origen venga de la provincia, de lo

1 Autora de Pensamiento crítico y políticas culturales en América Latina, profesora emérita de la Universidad de Salta (Argentina). Hace parte del Colectivo Modernidad/Colonialidad/Decolonialidad. nacional o de lo continental, observándose desde una perspectiva de modelo moderno occidental, es necesario cambiar el sitio desde donde nos imaginamos, así como desde donde observamos el globo. A partir de todos los territorios de tipo "periférico", enclaves que se entienden como exteriores al pensamiento eurocéntrico, nacen indagaciones del concepto de búsqueda equivalente, especialmente, en las últimas colonias que se independizaron de sus Estados opresores en la India, África, Oriente y América Latina.

La exploración de ordenamiento de escenarios de ideología americanos se remonta al siglo XV, cuando tuvo lugar el momento de aquel primer encuentro entre culturas, puesto que desde allí surgió el problema de diferencia y distancia entre los dominadores y sobre quienes quedaron bajo su control, situación que presentó dos problemáticas: la primera se relaciona con lo físico por la lejanía con el centro del poder, y la segunda de tipo temporal que abarcaba nociones de progreso/atraso, opositora del concepto de contemporaneidad, ya que ambas otorgan consistencia a la idea de relación entre civilización y cultura y entre 
cultura y naturaleza. De lo anterior se desprende el concepto de la fuerza del pensamiento moderno eurocentrado, que deberá reconsiderar la forma de vivir, de pensar y de crear hasta nuestros días.

La fundamentación mediante la cual se llevaron a cabo los objetivos de la ocupación colonial involucró suprimir de las culturas aborígenes americanas todo lo que tenía que ver con sus formas de vida y con las maneras de producción de sentido, que eliminó sus patrones de adquisición de conocimiento, así como de socialización de técnicas y de uso de materiales inherentes al entorno, con el propósito de ser modificados por otras formas de ver, instrumentos y materiales propios de la avanzada cultura colonizadora.

De estos términos de imposición cultural, se desprenderán las fundamentaciones estéticas que controlarían los modos de creación, como las formas de absorción de conocimiento, las "escuelas" artísticas y la construcción de vertientes estéticas, mediante las cuales se gestarán los modos de razonar que estarán en vigencia durante más de quinientos años.

Hoy no se reconocen de manera formal las realizaciones artísticas de las culturas étnicas preexistentes, las cuales son tenidas en cuenta solamente por su situación autóctona, connotación que se traduce como inferior de acuerdo con el valor universal que se le otorga a las obras de artistas reconocidos; entonces, los trabajos artísticos que se originan en el Tercer Mundo, por ejemplo en Latinoamérica, deben ajustarse a modelos exteriores, razón por la cual se observarán como asincrónicos, generalmente, sin sus connotaciones de pureza y autenticidad, puesto que los movimientos artísticos o los parámetros de innovación que los influencian llegan tarde al Tercer Mundo. Estas situaciones son las que han provocado que artistas suramericanos viajen al Primer Mundo para conocer de primera mano los orígenes del saber hacer como los otros. De allí que el concepto de colonialidad significa que creemos que "el bien, la verdad y la belleza" se encuentran en otro lugar y no en el propio (Palermo, 2003, p. 17).

Es, entonces, cuando se formula la pregunta ¿de qué manera es posible hallar las formas en las que se puede sintetizar el proceso de decolonialidad de la narrativa estética de origen eurocéntrico? Una respuesta básica puede radicar en lo que ha 
encontrado el pensamiento examinador suramericano, como es caso del Barroco latinoamericano, las antropofagias, lo transcultural y las diferentes opciones de hibridación. Respuesta que se puede conjugar con el conocimiento de la existencia de otras nociones mediante las cuales es posible encontrar nuevas instancias que se puedan interpretar como decoloniales, por ejemplo en los realizadores de arte que trabajan temas inherentes a la plástica, música, literatura, danza y arquitectura, a quienes se les puede formular la pregunta ¿de qué manera se encuentran en capacidad de interpretar sus contingencias creativas, con el objetivo de concebir nuevas maneras susceptibles de producir o perfilar otros tipos de narrativas que provean condiciones de alternatividad? La respuesta a esta inquietud es posible ubicarla en el postulado de lo "glocal"2 de Roland Robertson, que se puede entender como un primer acercamiento hacia un posible

2 Neologismo pronunciado por el sociólogo Roland Robertson, en una conferencia de 1997, titulada "Globalización y cultura indígena". El término se refiere, específicamente, a los "localismos globales", y según el estadounidense significa que "la globalización entraña la universalización del particularismo, así como la particularización del universalismo". nivel de equilibrio entre "la localización de lo global y globalización de lo local" (Palermo, 2003, p. 19), concepto del que se inquieren opciones de creación emancipadas y legítimas para la socialización de la identificación que tiene como origen el lugar, sin dejar de observar las nociones globales que amparan los procesos normales de creación.

De acuerdo con esto, es necesario no tener en cuenta las nociones inherentes al pensamiento eurocéntrico, que hablan de unos patrones diferenciales entre arte y artesanía, concepto que imbrica arte puro y arte impuro; el primero produce goce estético y el segundo se considera arte para turistas, cuyo valor se considera de uso. El artista crea obras irrepetibles y el artesano no crea, por cuanto desaparece como ente creador; el artista busca nuevas aproximaciones en su arte y el artesano no procura indagar y produce, generalmente, objetos artísticos en serie.

A partir de aquí, considero importante señalar que, dentro de la búsqueda de un espíritu de lo moderno, a comienzos del siglo pasado los artistas que protagonizaron las primeras vanguardias en Europa se nutrieron del arte étnico africano 
y oceánico como motivo de inspiración e indagación de un arte que no tuviera condiciones académicas. Razono que en este punto es importante aclarar que el arte étnico es producido por los aborígenes de un grupo determinado, mientras que las artesanías pueden ser realizadas dentro de su condición de producción seriada, ya sea por los mismos miembros de una comunidad étnica o por artesanos no "indígenas" que replican sus diseños. Los objetivos funcionales de estas artesanías pueden ser para uso ceremonial, goce estético o ser utilizados como elementos utilitarios. El interés por este tipo de arte en Europa se consideraba como algo exótico, situación que se convertiría en una búsqueda de nuevas aproximaciones estéticas y de movimientos vanguardistas, como es el caso del cubismo, el cual se resolvería conceptualmente a partir de la geometría que emerge de las máscaras africanas, como es el caso de la muestra de espécimen de arte étnico africano de Nueva Guinea, el cual se refleja en un retrato cubista (ver figuras 5 y 6) del malagueño, así como en la cara de la figura femenina localizada en el extremo superior izquierdo del óleo Las damas de Avignon de 1907.
Asimismo, sobresalen las siguientes obras que, junto con las anteriores, también hicieron parte de la exposición Primitivism in 20th Century Art: Affinity of the Tribal and the Modern, en el Museo MoMa de Nueva York, en 1984. De allí se destacan la pintura de la dama parisina de Matisse (ver figura 7), que surge de una máscara gabonesa, así como la escultura de Alberto Giacometti, que se nutre de una escultura de Tanzania (ver figura 8). De acuerdo con lo anterior, es posible apreciar que las realizaciones africanas se constituyen en la fuente de inspiración que permite a estos reconocidos artistas europeos realizar un proceso de interpretación para producir un nuevo tipo de obra. Se puede deducir, entonces, que este proceso de indagación sobre las máscaras y la estatuaria africana sentaba instancias de liberación del arte académico, así como búsquedas experimentales e ideológicas tanto en aspectos formales como de color, puesto que estos artistas obtuvieron ideas de otros lugares de tipo periférico, exteriores a las nociones eurocéntricas.

Creo que la noción de lo glocal fue aplicada antes de ser acuñado el término por Robertson por parte de 
reconocidos artistas de origen eurocéntrico a comienzos del siglo XX, como Henry Matisse, Raoul Dufy, Maurice de Vlaminck y André Derrain. Pues estos artistas valoraron de manera especial el arte primitivo, y lo apropiaron como fuente de inspiración tendiendo un puente de fecundación recíproca en el que emergió una producción artística de sentido global, a partir de una fuente de inspiración perteneciente a un universo particular. Hoy en día, entre los elementos que hacen parte de la fundamentación del arte moderno se encuentran los resultados de los procesos de búsqueda por lo nuevo, por lo que no se ha hecho antes, pues, el mundo del arte se desplaza bajo el ritmo de las modificaciones tecnológicas, y se nutre, continuamente, de los procesos de desarrollo que dan pie a nuevas realizaciones.

\section{Críticos del High-Tech, de Nadín Ospina, contextualizada por medio de las nociones sobre autoría de obra, intervención y apropiacionismo}

De acuerdo con esto, una de las nociones que han coadyuvado a forjar el hálito de las vanguardias ha sido la condición de ilusión, por cuanto el arte y la estética se han constituido en elementos que están en capacidad de forjar cambios en la sociedad actual, puesto que por medio de la posmodernidad ha sido posible avanzar en el reconocimiento del ser del Tercer y Cuarto Mundo, como un ente creador registrado dentro de la órbita artística global. Tal es el caso de la obra del artista conceptual colombiano Nadín Ospina, radicado en Bogotá, quien es graduado como maestro en Bellas Artes de la Universidad Jorge Tadeo Lozano. Dentro de la hoja de vida de Ospina, se destaca el primer premio que obtiene en el XXXIV Salón Nacional de Artistas de 1992, celebrado en Bogotá. La obra de este artista conceptual hace parte de las colecciones Ludwig Forum Aachen de Alemania, Art Gallery of Western Australia, así como de Lay Patchett Collection de Los Ángeles, entre otras entidades.

Ospina fue galardonado con la beca de la Fundación Guggenheim en 1997, y ha participado en numerosas exposiciones y certámenes artísticos internacionales y nacionales, como en la exposición Bizarros y Críticos, realizada en 1993, en la Galería Arte 19 de Bogotá, en la que se exhibió la obra Críticos del High-Tech, 
instalación compuesta por 25 ejemplares de la figura de Bart Simpson, realizados con unas dimensiones de $24 \times 10 \times 12 \mathrm{~cm}$ cada una.

Esta instalación de múltiples fue exhibida junto con distintos ejemplares de esculturas pertenecientes a otras series del mismo artista, como son los Críticos arcaicos, que eran Bart, Lisa y Margie, y Bizarros, que eran representaciones de figuras de animales, como hipopótamos, cocodrilos del Nilo y tortugas africanas.

Lo novedoso de esta exposición consiste en que las figuras de Bart Simpson no están realizadas en materiales modernos, sino que, por el contrario, son presentadas en arcilla cocida, en la manera de precolombinos, como si fuesen obras de artistas pertenecientes a antiguas culturas prehispánicas; de allí lo que pareciese a primera vista hegemónico, por medio de un remake, se convierte en parte de la iconografía occidental de consumo masivo.

Para contextualizar sobre lo que este tipo de instalación significa para un observador desprevenido dentro de la órbita artística colombiana de 1993, deseo, a continuación, citar un aparte del catálogo de la exposición Bizarros y Críticos, el cual fue escrito por el curador de la exposición Javier Gil (1993).

Piezas recién envejecidas, recién "precolombinizadas" nos entrega Nadín Ospina en su sorprendente exposición. Las artificiales figuras, elaboradas con la mayor precisión técnica, dejan ver las fisuras, resquebrajaduras y decoloraciones que imprime el tiempo en los objetos antiguos. En tal virtud la exposición nos produce la extrañeza propia de lo que es y no es al mismo tiempo, de lo serio e irónico, pero real y lo simulado. Varias reflexiones, entonces, podemos desprender de las operaciones artísticas ejecutadas por Nadín Ospina en torno al artista. Éste desaparece en su condición clásica ligada al buen oficio, al estilo, a la autoría, a una personalidad única e individual. Un nuevo concepto de artistas se insinúa, aquel que opera sobre cosas ya hechas, un operador de orden conceptual a partir de intervenciones mínimas. Casi que el mérito artístico - en su sentido clásico- le corresponde el artesano con su admirable técnica. Pone al descubierto la simulación generalizada que caracteriza a nuestra época. Baudrillard ha indicado que asistimos al fin de lo real-original y la consecuente escenificación del simple signo de las cosas. De la verdad a la apariencia, del arte al artificio. Nos hace ver la producción de autenticidad, la nueva industria del auténtico, la genuina producción del pasado. Ya no buscamos verdades originales, nos conformamos con simulaciones. 
Artificialidad de lo natural, naturalidad del artificio, lo culto y lo popular se emparejan en esta actitud. [...] Así mismo nos da qué pensar en otras direcciones: ¿nuevas deidades provenientes del mundo?, ¿redes de contaminación de imágenes y tiempos?, ¿proximidad absoluta de todas las cosas en la era posmoderna?, ¿burla de ciertos valores?, ¿crítica a una presunta, original incontaminada identidad poniendo en su lugar el sincretismo que sufre la misma identidad con diversas imágenes y tiempos? Quizá hoy se produce mayor identificación con las imágenes de los medios masivos que con una identidad remota y modificable.

La labor de Ospina, en la serie de múltiples Críticos del HighTech, consistió en tomar un objeto de consumo masivo, que, en este caso, es una figura de Bart Simpson, y mandarla a hacer nuevamente con las mismas tierras y métodos de moldeado, cocción y pulida mediante los cuales las antiguas culturas prehispánicas fabricaban sus objetos de decoración y culto. El objetivo conceptual de Ospina consiste en replantear la base del sentido original del objeto sobre el cual se va a trabajar, y modificar su connnotación primaria mediante un proceso de apropiacionismo, cuyo significado se amplirá más adelante.
Esta serie de obras "precolombinizadas", tituladas Críticos del High-Tech, al igual que otras similares del artista, son, generalmente, encargadas a hacer por el mismo artista a artesanos latinoamericanos, quienes son expertos en procesos de reproducción de obras precolombinas para museos especializados en arqueología, así como para turistas. En el caso específico de esta serie, el imaginario prehispánico en el que se basó el artista fue la cultura tayrona, que trabajaba antiguamente en cerámica, con especial esmero, elementos utilitarios, ceremoniales, así como figuras zoomorfas y antropomorfas.

Una vez es terminado el primer objeto artístico del Crítico del HighTech, que es la versión cero, y este es aprobado por Ospina, el artista da la orden de realizar, de manera individual, 25 ejemplares, serializando la obra con el objetivo de que sean exhibidos en la forma de una instalación.

¿En qué queda la autoría de la obra? ¿Pertenece al diseñador de Bart Simpson, Matt Groening, a los artesanos expertos que la realizaron, o a Ospina que conceptualizó su ejecución en técnicas precolombinas cuando su soporte de realización 
original corresponde a materiales actuales, como el plástico o caucho? Difícil de responder, pero lo que sí es un hecho es que Ospina firma estas obras y las numera, otorgándole a su obra el valor signo, lo que significa que asume su autoría.

Una vez explicado en qué consiste la obra Críticos del High-Tech, a continuación procederé a indagar sobre qué tipo de nociones artísticas se reflejan en la concepción delaserie de esculturas "precolombinizadas".

Para este efecto, me referiré a Jean Baudrillard, quien en Crítica de la economía política del signo escribe acerca del pintor Robert Rauschenberg, y relata que el estadounidense se copió a sí mismo cuando realizó las obras Factum I y Factum II en 1957 (ver figura 9), por cuanto pintó los dos cuadros de manera exacta, con iguales dimensiones de lienzo. Puesto que trazó de manera precisa la ejecución de las pinceladas, utilizó una misma paleta cromática y reflejó la misma estructura en ambas obras. El sociólogo francés afirma que Rauschenberg tenía muy claro que, aunque los dos cuadros eran idénticos, eran, sin embargo, diferentes, puesto que se trataba de un testimonio de dos momentos y tiempos diferentes y que debido a esto mantienen su valor intrínseco dentro de la órbita comercial o del mercado del arte. De acuerdo con este concepto, no se trata de original y copia, sino de dos obras originales.

Asimismo, considero también importante traer a la memoria el caso de Marcel Duchamp cuando le coloca bigotes a una reproducción de la Monalisa, de Da Vinci (ver figura 10), pues, en este caso el francés toma lo que ya es considerado obra de arte y se lo apropia con el fin de cambiar sus particularidades y su autoría. Rauschenberg, por su parte, consciente de la acción realizada por Duchamp, continúa experimentando con nuevas posturas artísticas, decide responderle al mundo del arte interviniendo un dibujo de Willem de Kooning (ver figura 11), desdibujándolo; el resultado de este acto fue la creación de una obra nueva, a partir de la destrucción de la obra intervenida parcialmente. De acuerdo con esto, Duchamp realizó modificaciones en una reproducción y Rauschenberg efectuó un proceso de intervención, más exactamente deconstruyó una obra que por sí ya era un original.

Una vez conocidos los referentes artísticos bajo los cuales se contextualizan los conceptos de 
modificación de características de una obra de arte, que implican un cambio de autoría, así como las nociones de intervención y deconstrucción en un trabajo artístico, a continuación, procederé a indagar acerca de qué tipo de postulados teóricos se reflejan en la concepción de la serie de esculturas precolombinizadas, tituladas Críticos del HighTech, y de qué manera emergen en ellas conceptos de autoría y apropiacionismo. Para este efecto, me voy a referir a un autor: se trata de Nicolas Bourriaud (2006b), quien en Estética relacional habla sobre las nociones de papel del artista y quien, mediante un proceso solitario de creación, busca un concepto que sea preponderante en el arte. También escribiré sobre los temas que comprenden la autoría, el apropiacionismo y el sentido del lugar de exhibición de una obra.

Como se ha podido intuir, la obra del artista conceptual Nadín Ospina se caracteriza por realizar acciones de apropiacionismo, que significa navegar por otro signo y construir otro significado. Este concepto se refiere a modificar en una segunda instancia el sentido original del objeto u obra en cuestión, con el objetivo de inculcarle cambios que conmutarán la base de su sentido, o sea, su connotación primaria. La noción de apropiacionismo dentro del arte tiene su relación con los ready-made. Pues Ospina toma lo que ya se conoce como un objeto de divertimento para niños de consumo masivo, se apodera de este con el fin de de modificar sus propiedades y lo reutiliza bajo otros contextos modificando su autoría, convirtiéndolo en obra de arte por medio de su firma.

Escribe Bourriaud:

El arte del siglo XX es un arte del montaje (la sucesión de imágenes y del recorte, la superposición de imágenes). El fin del telos modernista (las nociones de progreso y de vanguardia) abren un nuevo espacio para el pensamiento; en adelante se trata de darle un valor positivo al remake, articular usos, poner en relación formas, en lugar de la búsqueda heroica de lo inédito y de lo sublime que caracterizaba el modernismo (2009, p. 49).

Como se puede observar, Ospina utiliza la técnica de sucesión de imágenes por cuanto realiza una serie de múltiples, se basa en el remake, porque no realiza la búsqueda de lo excelso en el arte ni crea con sus propias manos una serie de esculturas de características únicas, 
sino que se basa en una imagen de consumo masivo conceptualizada por una segunda persona, que luego es mandada a rehacer por parte de una tercera persona, concepto que nos lleva a la idea de apropiacionismo. Ospina también busca reflejar en su obra nociones de vanguardia, y creo que lo logra ya que nunca en Colombia se había visto un tipo de obra que implementara este tipo de teorías; pero lo que es curioso es que, como se mencionó, en el ámbito internacional sí se había visto.

Continúa Bourriaud explicando:

El remixador se ha vuelto más importante que el instrumentista, la fiesta rave más excitante que un recital. La supremacía de las culturas de la apropiación y del reprocesamiento de las formas introduce una moral: las obras pertenecen a todo el mundo (2009, p. 49).

Como se ha podido ver, es posible interpretar el trasfondo teórico de Críticos del High-Tech por medio de lo expresado por Bourriaud. Pues, en este caso, Ospina asume el papel de remixador, ya que utiliza una imagen del Primer Mundo, la cual es mandada a fabricar por parte de artesanos del Tercer Mundo, bajo técnicas de una cultura ancestral prehispánica desaparecida, de allí que esta serie, producto de la cultura de la apropiación y su reprocesamiento, pertenezca a "todo el mundo", aun cuando el artista asuma la autoría de las obras objeto de estudio de este ensayo.

Concluye Bourriaud:

La exposición ya no es el resultado de un proceso, su happy end, sino un lugar de producción. El artista pone allí herramientas a disposición del público [...] Aunque rehacen las formas académicas de la exposición, los artistas de los años noventa consideran el lugar de exhibición como un espacio de cohabitación, un escenario abierto a medio camino entre el decorado, el estudio de filmación y la sala de documentación (2009, p. 87).

Como se dijo, el lugar de producción de la serie Críticos del HighTech es Latinoamérica; se trata de una muestra de objetos artísticos que, desde una primera mirada desprevenida, se asimilan al arte precolombino. Ospina diseña en una sala de exposición de una galería de arte una instalación que se asemeja a un set de filmación para comerciales. Estos elementos confirman la apropiación que hace el artista de las teorías de un moderno curador francés.

Para complementar las nociones expuestas, me voy a referir al 
concepto valor de diferencia, el cual es expuesto por Baudrillard en $E l$ gestual y la firma: semiurgia del arte contemporáneo:

No se ve la obra sino que se reconoce y evalúa dentro del sistema de signos. La obra se convierte con la firma en un "objeto cultural". Transferida la legitimidad al acto de pintar, éste no puede sino hacer infatigablemente la prueba de sí mismo [...] no siendo ya el término final de esta serie el mundo que representar, sino el sujeto siempre ausente, deviene una necesidad absoluta señalar que este sujeto como tal y significar al mismo tiempo la obra como objeto de este sujeto: tal es la función de la firma [...] "El cometido esencial entonces es preservar la autenticidad del signo" (1974, pp. <10-111).

En el caso de la serie Críticos del High-Tech, la firma de Ospina traslada a esta obra dentro del entorno diferente del objeto, por lo que, según Baudrillard, se convierte en un modelo, al cual un signo visible, que es la firma, le otorga un valor de diferencia sobresaliente. Se aclara que no es el valor de sentido lo primordial: se trata de un valor de "diferencia", que motiva la ambigüedad del mismo signo, que ayuda a reconocer y evaluar la obra dentro de un sistema de signos, que se constituye en una serie, aspecto esencial que hace parte de la búsqueda y construcción del proceso creativo de un artista.

Quiero recordar, antes de concluir este texto, una frase de Bourriaud perteneciente a Estética relacional, que considero se aplica perfectamente a Ospina en su papel de artista conceptual. En este caso, Ospina se convierte en un "semionauta, o sea un artista contemporáneo que inventa trayectorias entre signos" (2008, p. 142).

\section{Conclusiones}

Hoy en día, el arte busca nuevas instancias de movimiento y comprobación entre las variadas expresiones artísticas del globo, que se expande hacia un proceso de acentuación común de educación visual entre lugares distantes. El surgimiento y establecimiento de los distintos creadores que hacen parte del Tercer y Cuarto Mundo, debido al espacio que abrieron los movimientos posmodernos, ha permitido un contagio mundial de signos entre los principales continentes. Por esto, se ha evolucionado en pro de la equivalencia entre creadores de los diferentes territorios que hacen parte del mundo, sin dejar de ser importante que se hayan gestado 
para propiciar la creación de más espacios de comercio dentro de la órbita artística. La modificación cualitativa que ha tenido lugar se ha visto reflejada en nuevos patrones de reconocimiento de las creaciones artísticas provenientes de los países subdesarrollados, al igual que el reconocimiento del papel del artista como tal; todo esto se le debe a la misma singularidad de la inercia propia de la modernidad.

Para cerrar los conceptos que atañen a la conclusión y dialogar sobre la obra de Ospina, deseo citar unos apartes del texto titulado "El exotismo pop", el cual fue publicado en Lápiz: Revista Internacional del Arte en 2001. Este artículo que versa sobre la obra del artista conceptual bogotano fue escrito por el curador y crítico de arte de origen español, Eduardo Pérez Soler, quien consideró que, por medio de sus pensamientos, el lector de este texto puede compendiar algunas nociones sobre los elementos que se esconden detrás de la obra de Ospina.

Es posible afirmar que el descubrimiento de la "alteridad" por parte de Occidente tuvo lugar con los grandes viajes de los exploradores europeos a partir de los siglos XIV y XV, precisamente cuando se comenzaban a gestar los principios científicos, políticos y económicos que dieron origen a la modernidad. [...] A la larga, la creación "exótica" terminó por ocupar un lugar periférico en los sistemas del arte occidental. Evaluadas desde una óptica etnocéntrica y evolucionista las creaciones de las culturas no occidentales fueron consideradas como productos de pueblos atrasados y salvajes [...] Las propuestas de Nadín Ospina intentan poner en entredicho las categorías creadas para clasificar los productos creativos. [...] Nadín Ospina termina por convertir lo hegemónico en exótico: iconos de la cultura occidental, como los personajes de Walt Disney o Matt Groening, son equiparados a las obras de los artistas anónimos de culturas primitivas, para adquirir así un carácter de "otro". En las obras de Ospina las coordenadas que definen el centro y la periferia pierden su sentido. [...] Es un exotismo deseable, despojado de su esencia, y que no pone en cuestión la preeminencia del capitalismo y su ideología. Es una "alteridad" que no genera conflictos, en la que todos ya seamos morenos, negros o amarillos, nos parecemos enormemente a Mickey o a Bart Simpson (2001, pp. 47-51).

Para concluir, quiero interpretar por medio del pensamiento de Ospina lo afirmado por Bourriaud. En síntesis, la obra de este artista conceptual busca el valor del objeto en el resultado de sus procesos de 
intervención y repetición. Su método utiliza la apropiación al utilizar un material con historia ancestral ligado a un pasado precolombino; para hacer parte de los lenguajes de la plástica globalizada del momento, sus postulados teóricos buscan cuestionar los sistemas de producción, el valor de la autoría y el concepto de originalidad.

\section{Referencias}

AA. VV. (2010). Arte: la guía visual definitiva, 1900-1945. Reino Unido: Dorling Kindersley.

AA. VV. (2010) Arte: la guía visual definitiva, 1945-Actualidad. Reino Unido: Dorling Kindersley.

Baudrillard, J. (1974a). El gestual y la firma: semiurgia del arte contemporáneo. En Crítica de la economía política del signo (pp. 108-125). Buenos Aires: Siglo XXI.

Baudrillard, J. (1974b). La subasta de arte: intercambio/signo y valor suntuario. En Crítica de la economía política del signo (pp. 88-105). Buenos Aires: Siglo XXI.

Baudrillard, J. (1974c). Más allá del valor de uso. En Crítica de la economía política del signo. Buenos Aires: Siglo XXI.

Baudrillard, J. (1998). La ilusión y la desilusión estética. En La ilusión y la desilusión estética (pp. 44-69). Caracas: Monte Ávila.

Baudrillard, J. (1998). La simulación en el arte. En La ilusión y la desilusión estética (pp. 25-32). Caracas, Monte Ávila.

Bourriaud, N. (2006a). La forma relacional. En Estética relacional. Buenos Aires: Adriana Hidalgo.

Bourriaud, N. (2006b). Hacia una política de la formas. Estética relacional. Buenos Aires: Adriana Hidalgo.

Bourriaud, N. (2009). Posproducción. Buenos Aires: Adriana Hidalgo.

Benjamin, W. (1989). La obra de arte en la época de su reproductibilidad técnica. En Discursos ininterrumpidos I. Buenos Aires: Taurus.

Bishop, C. (2010, 21 de agosto). Antagonismo y estética relacional [en línea]. Consultado el 17 de noviembre de 2012 en <http:// salonkritik.net/10-11/2010/08/ antagonismo_y_estetica_relacio. php>. 
Brea, J. L. (2010). Las tres eras de la imagen. Madrid: Akal.

Chartier, R. (1992). El mundo como representación. Historia cultural: entre práctica y representación. Barcelona: Gedisa.

Debord, G. (2007). La sociedad del espectáculo. Valencia: Pretextos.

Duerden, D. (2000). The discovery of the african mask. Research in African Literatures, 4, 29-47.

El Ojo de la Paradoja (2012, 14 de marzo). Con un papel en blanco [en línea]. Consultado el 11 de noviembre de 2012 en $<$ http://elojodelaparadoja.blogspot.com/2012/03/conun-papel-en-blanco.html>.

Foucault, M. (1994). ¿Qué es un autor? París: Gallimard.

García Canclini, N. (2010). Valorar el arte: entre mercado y política. En La sociedad sin relato (pp. 129-150). Buenos Aires: Katz

García Canclini, N. (1995). Consumidores y ciudadanos: conflictos multiculturales de globalización (pp. 30-31). México: Grijalbo.

Gruzinski, S. (2007). El pensamiento mestizo. Cultura amerindia $y$ civilización del Renacimiento. Barcelona: Paidós.

Heard, G. (1980). Pintura y escultura en Europa 1880-1940. Madrid: Cátedra.

Jameson, F. (1991). El posmodernismo o la lógica cultural del capitalismo avanzado. Barcelona: Paidós Ibérica.

Jameson, F. (1996). Teoría de la posmodernidad. Madrid: Trotta.

Lippard, L. (1996). Six years: the dematerialization of the art object 1966-1972. Berkeley: Berkeley University of California Press.

Los 40 años de la muerte de Marcel Duchamp [en línea]. Consultado el 11 de noviembre de 2012 en <http:// www.cambio. com.co/culturacambio/769/ARTICULO-WEB-NOTA_INTERIOR_CAMBIO-4034475. html>.

Manijeh, V. (2010, 22 de noviembre). Research on Twins in Art \& Photography [en línea]. Consultado el 11 de noviembre de 2012 en <http:// www.aadip9.net/manijeh/2010/11/ research-on-twins-in-art-photo. html>. 
Medina, Á. (2000). Nadín Ospina: refiguraciones. Bogotá: Pretextos.

Mercado Libre. Bart Simpson: muñeco original Fox 1990 [en línea]. Consultado el 11 de noviembre de 2012 en <http://articulo.mercadolibre.com.ar/MLA-449023294-bartsimp son-muneco-originalfox-1990-_JM?redirectedFromPare nt=MLA443099633>.

Mouffle, C. (1998). Deconstrucción y pragmatismo. Buenos Aires: Paidós.

Quijano, A. (2003). Colonialidad del poder, eurocentrismo y América Latina. En Lander, E. (comp.). Colonialidad del saber, eurocentrismo y ciencias sociales (pp. 201-246). Buenos Aires: Clacso.

Ospina, N. (1993a). Bizarros y críticos. Instalación en la Galería Arte 19 [en línea]. Consultado el 11 de noviembre de 2012 en <http://www.oocities.org/nadinospina/Bizarros_y_ criticos.html>.

Ospina, N. (1993b). Críticos del High-Tech [en línea]. Consultado el 11 de noviembre de 2012 en $<$ http://www.colarte.com/colarte/ foto.asp?idfoto $=161490>$.
Ospina, N. (2010). Arqueología y turismo [en línea]. Consultado el 11 de noviembre de 2012 en $<$ http://www.nadinospina.com/nadin-ospina_arqueologia_y_turismo.html>.

Palermo, Z. (2009). El arte latinoamericano en la encrucijada decolonial. En Arte y estética en la encrucijada decolonial (pp. 7-2). Buenos Aires: Ediciones de Signo.

Pérez, S. (2001). El exotismo pop. Revista Lápiz, 171, 47-51 [en línea]. Consultado el 17 de noviembre de 2012 en <http://www.nadinospina. com/nadin-ospina_lapiz.html>.

Picasso, P. (1907). Las damas de Avignon. Nueva York: Colección MoMA [en línea]. Consultado el 11 de noviembre de 2012 en <http:// www.acsu.buffalo.edu/ jconte/ Images/Picasso_Demoiselles.jpg >.

Rancière, J. (2005). Sobre políticas estéticas. Barcelona Museu d'Art Contemporani de Barcelona: Bellaterra.

Rancière, J. (2010a). El espectador emancipado. En El espectador emancipado (pp. 7-29). Buenos Aires: Manantial. 
Rancière, J. (2010b). Las desven- Zielinski, S. (2012). Hallazgos forturas del pensamiento crítico. En tuitos, en vez de búsquedas vanas. El espectador emancipado (pp. 84- En Arqueología de los medios. Hacia 114). Buenos Aires: Manantial.

Rancière, J. (2010b). Las paradojas del arte político. En El espectador emancipado (pp. 9-84). Buenos Aires: Manantial.

Robertson, R. (1998). Glocalización: tiempo-espacio y homogeneidad-heterogeneidad. Madrid: Trotta.

Roland, B. (1987). La muerte de un autor. Barcelona: Paidós.

Walter, B. (s. f.). El autor como productor (trad. Bolívar Echeverría) [en línea]. Consultado el 24 de noviembre de 2012 en <http://escenacontemporanea.com/2011/circulode-espectadores/_docs/el_autor_ como_productor.pdf $>$. el tiempo profundo de la visión y la audición técnica (pp. 21-58). Bogotá: Universidad de los Andes.

Zielinski, S. (2012). Luz y sombra. Consonancia y disonancia: Atanasius Kircher. En Arqueología de los medios. Hacia el tiempo profundo de la visión y la audición técnica (pp. 221-280). Bogotá: Universidad de los Andes.

Zizek, S. (1998). Multiculturalismo o la lógica cultural del capitalismo multinacional'. En Jameson, F. y Zizek, S. Estudios culturales. Reflexiones sobre el multiculturalismo. Buenos Aires: Paidós. 

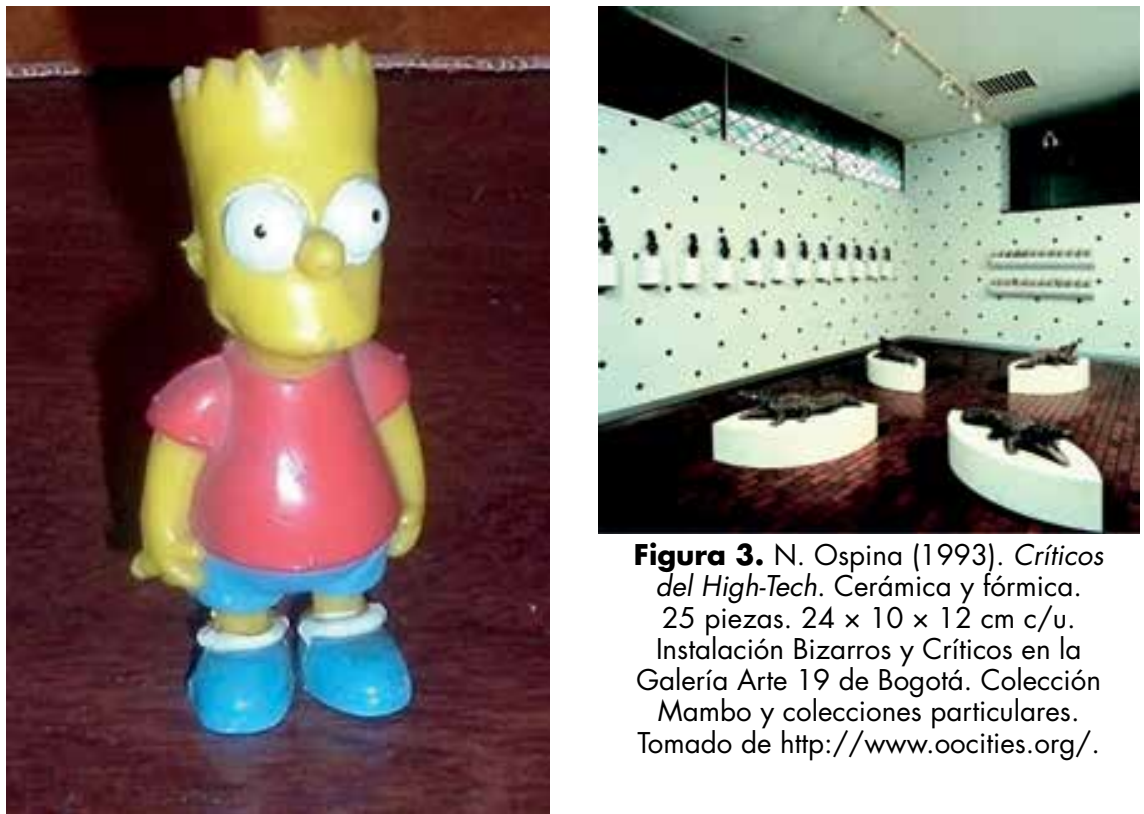

Figura 3. N. Ospina (1993). Críticos del High-Tech. Cerámica y fórmica. 25 piezas. $24 \times 10 \times 12 \mathrm{~cm} \mathrm{c} / \mathrm{u}$. Instalación Bizarros y Críticos en la Galería Arte 19 de Bogotá. Colección Mambo y colecciones particulares. Tomado de http://www.oocities.org/.

Figura 1. Referente comercial del muñeco en plástico de Bart Simpson, creación de Matt Groening. Tomado de http://articulo.mercadolibre.com.ar.
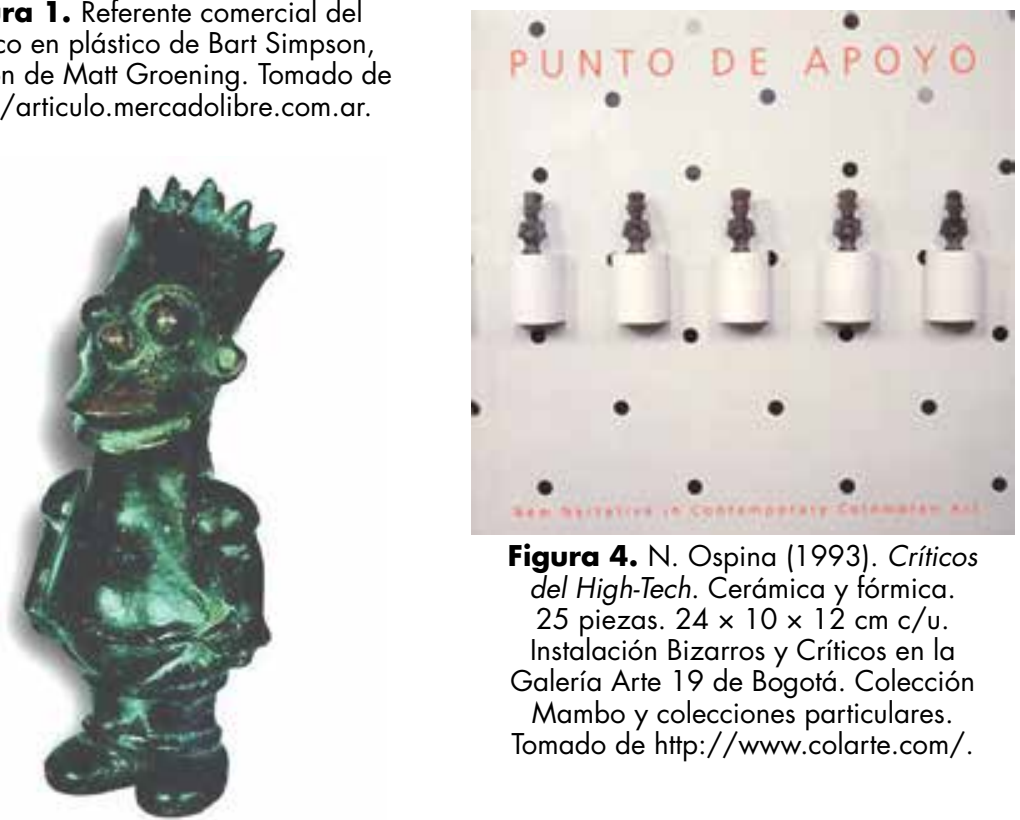

Figura 4. N. Ospina (1993). Críticos del High-Tech. Cerámica y fórmica. 25 piezas. $24 \times 10 \times 12 \mathrm{~cm} \mathrm{c} / \mathrm{u}$. Instalación Bizarros y Críticos en la Galería Arte 19 de Bogotá. Colección Mambo y colecciones particulares. Tomado de http://www.colarte.com/.

Figura 2. N. Ospina (1993). Críticos del High-Tech. Cerámica y fórmica. 25 piezas. $24 \times 10 \times 12 \mathrm{~cm} \mathrm{c} / \mathrm{u}$. Instalación Bizarros y Críticos en la Galería Arte 19 de Bogotá. Colección Mambo y colecciones particulares. Tomado de http://www.nadinospina.com/. 


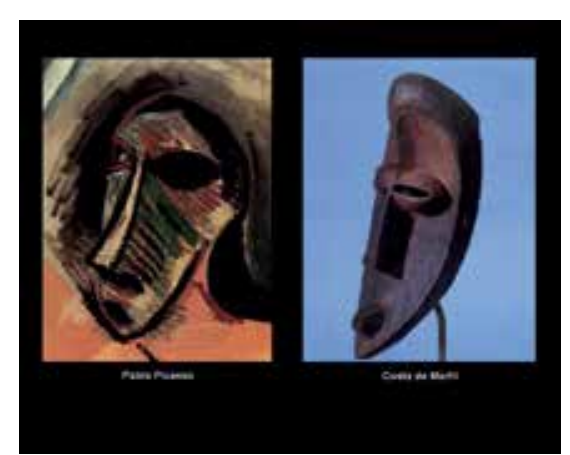

Figura 5. Doble imagen de máscara étnica de Nueva Guinea y pintura análoga de Pablo Picasso, obras que hicieron parte de la exposición Primitivism in 20th Century Art: Affinity of the Tribal and the Modern, en el Museo MoMA de Nueva York, en 1984. Tomado de W. Stanley Rubin (1984). Primitivism in 20th Century Art: Affinity of the Tribal and the Modern William. Nueva York: MoMA.

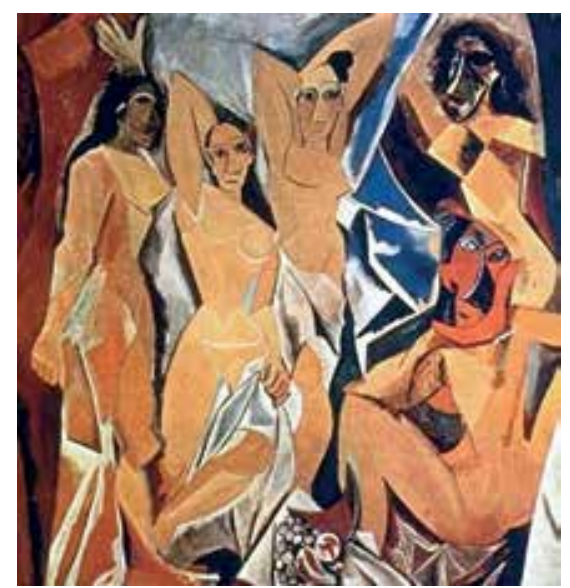

Figura 6. P. Picasso (1907). Las damas de Avignon, Museo la MoMS, Colección MoMA, Nueva York. Tomado de http://www.acsu.buffalo.edu/.

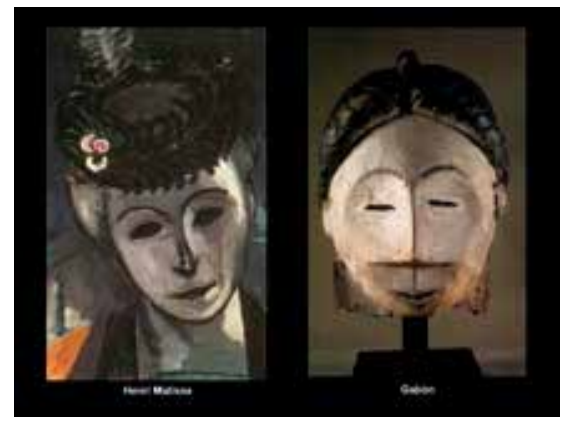

Figura 7. Doble imagen de Máscara étnica, de Gabón, y pintura análoga de Henry Matisse, obras que hicieron parte de la exposición Primitivism in 20th Century Art: Affinity of the Tribal and the Modern, en el Museo MoMA de Nueva York, en 1984. Tomado de W. Stanley Rubin (1984). Primitivism in 20th Century Art: Affinity of the Tribal and the Modern William. Nueva York: Museo MoMA.

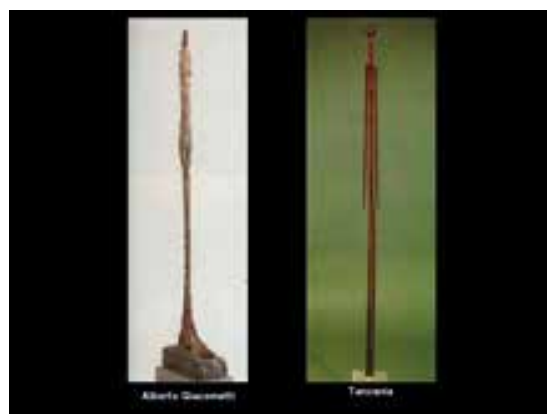

Figura 8. Doble imagen de Escultura étnica de Tanzania y escultura análoga de Alberto Giacometti, obras que hicieron parte de la exposición Primitivism in 20th Century Art: Affinity of the Tribal and the Modern", en el Museo MoMA de Nueva York, en 1984. Tomado de W. Stanley Rubin (1984). Primitivism in 20th Century Art: Affinity of the Tribal and the Modern William. Nueva York: Museo MoMA. 


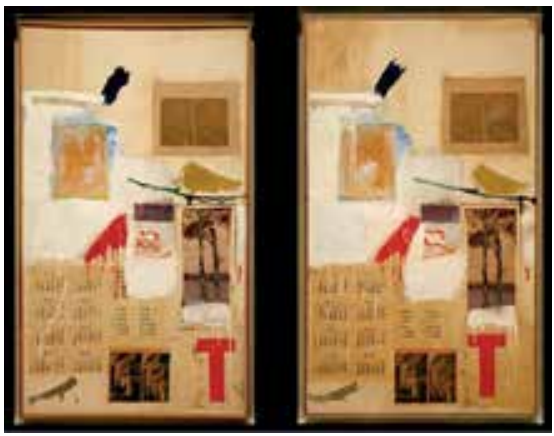

Figura 9. R. Rauschenberg (1957). Factum I \& II, Museum of Contemporary Art, The Panza Collection, Los Ángeles. Tomado de http://www.aadip9.net/.

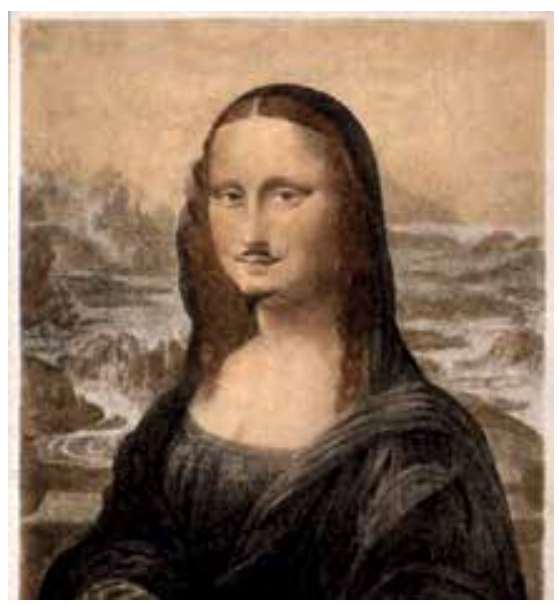

Figura 10. M. Duchamp (1919). L.H.O.O.Q. o La Monalisa con bigotes, Museo del Louvre. Tomado de http://www.cambio.com.co/.

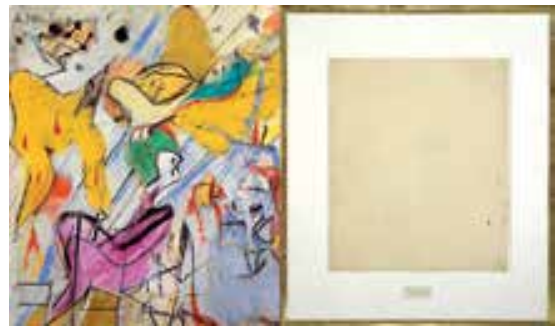

Figura 11. A la izquierda, pintura de Willem de Kooning, y a la derecha la misma obra intervenida de Kooning por parte de Robert Rauschenberg, la cual se titula Erased de Kooning, de 1953. Tomado de http://elojodelaparadoja.blogspot.com/. 
- Críticos del High-Tech, de Nadín Ospina - Diego Carrizosa Posada 